
\title{
R Reserach S Surare \\ Exploring potential benefits of communication training with standardised patients for medical students
}

Johan Isaksson ( $\nabla$ johan.isaksson@neuro.uu.se )

Uppsala University

Julia Krabbe

Uppsala University

Mia Ramklint

Uppsala University

\section{Research Article}

Keywords: communication skills training, education, medical students, standardised patients

Posted Date: April 22nd, 2021

DOl: https://doi.org/10.21203/rs.3.rs-429204/v1

License: (c) (i) This work is licensed under a Creative Commons Attribution 4.0 International License.

Read Full License 


\section{Abstract}

Background: Physicians' communication skills (CS) are important for improving patient-centred care. The aim of this study was to evaluate simulation training in difficult consultations with actors as standardised patients (SPs) for training CS with medical students, as regards both student satisfaction and effects on CS used.

Methods: In this mixed-method study, quantitative data from student evaluations ( $N=93)$ and results from practical examinations $(N=73)$ were compared between medical students who practiced CS in challenging situations through simulation training with SPs with students from previous term when SPs were not used in the training. The number of CS used during each included video-taped practical examination was counted. Differences in number of CS behaviours (active listening, empathy and motivational efforts) were examined using a MANCOVA. Further, 23 students were interviewed in focus groups about their experiences of simulation training using SPs; interviews were analysed with content analysis.

Results: Students who participated in simulation training with SPs were more content with the course. There was no between-group difference in the number of CS used in practical examinations. In the focus groups, students reported that actors as SPs made the simulations more realistic. Elements such as actor flexibility in changing behaviours during roleplay and being exposed to different difficult consultations and emotions were regarded as valuable.

Conclusion: Implementing actors as SPs in the medicine programme was appreciated and seemed to add elements to the learning process of CS. No firm conclusions can be drawn regarding the lack of effect of SPs on CS, considering the absence of baseline levels of CS use. Future research should use a randomised control design.

\section{Introduction}

Communication skills (CS) are regarded as an important element of the medical consultation and make up part of patient-centred care, where physicians employ active listening [1-4]. Active listening includes encouragement, open-ended questions, reflections and summarising the patient's words and the emotions expressed or showed [2, 4]. Active listening also includes aspects of empathy, i.e., understanding patient experiences, concerns and perspectives, combined with a capacity to communicate this understanding [2,5-6]. Good CS in a physician have been associated with increased treatment adherence among patients [7, 8], improved patient satisfaction [9-11], reduced perceived pain and anxiety among patients, as well as benign physical outcomes such as reduced bronchial activity in asthmatic patients and increased physical function in postoperative patients [10]. Motivational interviewing (Ml), encompassing both active listening and empathic communication, is a client-oriented method developed to promote behavioural changes in a patient, with a focus on exploring patient ambivalence [12]. MI has been shown to be useful in helping patients make lifestyle changes, such as 
cessation of smoking or drinking [13]. Given the importance of CS for patient adherence, satisfaction and health, it is of great importance to include communication training in the education of future health professionals, such as medical students.

Dispiritingly, some studies have reported that medical students' empathy decreases during medical school $[5,14,15]$. Specific aspects linked to a decline in empathy levels include feelings of pressure or exhaustion and the need for detachment from the more emotionally challenging aspects of medicine [16, 17]. Some consultations are more challenging than others, including giving bad news or presenting negative information to a patient, or talking with an unhappy, angry, or unmotivated patient. These consultations require more CS from the healthcare provider. If information is delivered in an inadequate way, it may result in increased suffering, misunderstanding and bitterness in the patient, whereas if it is done well it can help the patient understand, accept and adjust to the information [18]. Previous research has shown that delivering negative information to patients provokes more cardiovascular and perceived stress among medical students [19] and the students may instinctively react defensively or even with hostility [20]. It is therefore essential for medical students to learn to recognise patient anger or displeasure and techniques for deescalating such a situation [21]. In order to prepare students for managing such situations, adequate communication tools are needed. Fortunately, CS can be improved.

CS is an accepted subject in medical school curriculums. Traditionally, lectures have been the primary teaching aid for training students in CS [22]. However, such teaching does not open up for discussion or give students the chance to practice the skills [23]. While small groups with peer roleplaying give students the opportunity to practice and receive direct feedback on their skills, such teaching depends on the students' abilities or inabilities to portray patients and give realistic responses [23]. The use of standardised patients (SPS) in case simulations has been recommended for training CS [23], and SPs are now widely used in medical schools [24,25]. SPs are usually actors who have been trained to portray patients. SPs are used by medical educators in both formative and summative objective structured clinical examinations [26]. Though there is growing literature focusing on the use of SPs in the training of CS, most studies focused on a selected group of skills (e.g., delivering bad news) or used SPs as examiners of students' CS. The use of SPs in practicing conveying bad news has been shown to be valued by health workers [27] and students [28,29]. However, as concluded in a recent systematic review, there is very little published work assessing the impact of SP use in medical educations and also evaluating any behaviour change in the participants [30]. Although a few studies have included CS outcomes in students being trained in taking a medical history [31] or breaking bad news to a SP [32, 33], indicating some positive effects, studies seldom include a wider range of challenging behaviours or explore both feasibility and behavioural effects.

To rectify these limitations in previous research, we implemented a teaching method for training patientcentred CS in challenging situations using SPs during the eighth term in the medicine programme. The aims of this mixed-method study were to evaluate if simulation training using actors as SPs resulted in 1) better student evaluations and/or 2) an increase in use of CS, i.e., active listening, increase empathy and use of Ml techniques, as compared with students from previous term, during which peer roleplay (instead 
of SP roleplay) was used to train the challenging situations. A third aim (3) was to explore, via interviews, students' experience of simulation training using SPs.

\section{Method}

\section{Procedure}

All students at the medicine programme at Uppsala University receive training in CS during the first, fourth and eighth term. During the eighth term, a three-day course, Communication skills in challenging situations, is held. The course comprises lectures on CS, such as using active listening in challenging situations, showing empathy and using $\mathrm{Ml}$, as well as theory on conversation skills needed for patientcentred communication in challenging situations. Following the lectures, students roleplay with peers in small groups (up to 10 students) to practice the skills. A new teaching method for training communication with SPs (actors) in case simulations was introduced during the autumn of 2019. This was done to increase the opportunities for students to practice their skills in challenging situations. At the end of each term, the medical students evaluate the courses taken by grading them. These data were included to achieve the present study's first aim (i.e., comparing student evaluations before and after the simulation training with SPs was introduced). During the eighth term, students have a practical examination, consisting of a clinical examination in psychiatry where each student acts as the physician in a conversation with a SP (an actor) and performs a full consultation. The examination is filmed, if the student permits this. To achieve aim 2, video recordings from the practical examinations were used for assessing CS in medical students, before and after the implementation of the simulation training with SPs. Lastly, to achieve aim 3, students participating in the new teaching method for training communication with SPs in case simulations during autumn 2019 were invited to be interviewed in focus groups about their experiences, in early 2020.

\section{Participants}

All students in the medicine programme are asked to give written evaluation, see below, on all courses taken. However, there is large attrition and many students do not complete these forms. For this study, we used the evaluations from spring 2019 (before simulation training, 57 included out of 105, response rate $=54 \%$ ) and autumn 2019 (after simulation training, 36 included out of 84 , response rate $=43 \%$ ). Video recordings from practical examinations from two different terms, before and after the simulation training had been introduced $(N=183)$, were initially included. Of these, 70 videos were excluded because the actor was portraying a patient suffering from schizophrenia, since this would usually initiate less use of CS, 30 were excluded due to lack of written consent for permission to use the film for educational development, and in 10 cases the video was incomplete. Thus, 73 films (40\%) were included, of which 46 (15 males and 31 females) films were with students before the new training with SPs was implemented and 27 ( 13 males and 14 females) were from after simulation training with actors. All students from the autumn term 2019 were invited to focus groups, of whom $N=23(27 \%)$ agreed to participate (split into three focus groups). Thus, the study sample was $N=93$ for the first aim, $N=73$ for the second aim, and 
$N=23$ for the third aim. The study was approved by the Swedish Ethical Review Authority, Dnr 201905908.

\section{Training with SPS}

The simulations were conducted in groups of six to eight students, one SP (a professional actor who has been trained to portray patients consistently), and one supervisor for each scenario. The student groups moved between four rooms, each of which presented a different case. The student groups spent 90 minutes in each room and two to four students got the chance to act as the doctor for each specific case. The four cases were: Telling an elderly woman with aggressive colon cancer that she is dying (using empathic responses); handling negative patient reactions with a woman who is unhappy with the care she has received from her doctor and trying to find a way forward (using active listening); discussing a rehabilitation plan with a reluctant middle-aged man with back pain who has been on paid sick leave (using MI tools and active listening); and motivating a reluctant young man with alcohol problems to change his lifestyle (using MI tools and active listening). For a more detailed description of the cases, see

Supplementary Table 1. The students who were not active as the doctor in the simulations were given the task to observe and give feedback to their peers. The student who was acting as the doctor received immediate feedback from the supervisor, who was either an experienced physician or an experienced psychologist, as well as from their peers and the SP.

\section{Measures}

Yearly evaluation form

Out of the eight questions (with six sub-questions) that are included in the evaluation form, we chose four items deemed as most relevant for the study aim: 'What is your overall review of the course?', 'How satisfied are you with the seminars/work in groups?', 'Too what degree do you think the teachers have given you valuable feedback on your work?', and 'Too what degree do you think you were given the opportunity to be active?'. All items were rated from $1=$ 'not (content) at all' to $6=$ 'very content/much'.

Video recordings of consultations (use of CS)

The six different cases played by SPs included in the practical examinations represented different disorders, such as depression, peripartum depression, bipolar disease in manic phase, anxiety and alcoholism. The patient cases were designed to be challenging in various ways for the student acting as the physician (e.g., hostile patient, patient reluctant to change unhealthy behaviour, patient burdened with guilt, patient having doubts about treatment). The consultation part of the examination was limited to 20 minutes, after which the student was asked by the examiner to give an evaluation of the patient's psychiatric status and report his/her clinical evaluation. The whole consultation was examined and CS were evaluated. There are several rating checklists for CS described in the literature, but no gold standard [34]. In this study, the videotapes from the recorded examinations were coded with a scoring system using behavioural counts based on patient-centred interviewing [4], created specifically for this study. The 
scoring system included a checklist with three main categories: Active listening (encourages, reflections, summarises, asks open-ended and closed-ended questions, asks for permission), empathy (verbalises the patient's feelings, validates and normalises, shows support and care), and motivational efforts (explores what is positive/less positive about the current situation, what is less positive/positive about changing the current situation, clarifies the need for change and how change will happen), see Supplementary Table 2. Each time a behaviour was shown, a mark was made in the protocol and when the film ended, all behaviours within each category were added together.

There were two exceptions. The first was within Active listening, where the sub-category 'Closed-ended questions' was not added to the others. Instead, the relation between the sub-categories 'Open-ended questions' and 'Closed-ended questions' was calculated as a quota. The second was within Empathy, in the sub-category 'Shows support and care', where students could receive a maximum of five points for five pre-defined types of behaviour. To ensure reliable ratings, JK and MR initially reviewed and rated five videos independently to evaluate interrater reliability. MR is a psychiatrist and professor teaching CS and JK is a medical student in term ten, with two years' experience of teaching CS to medical students in terms one and four. After these five scorings, a high interrater reliability could be shown with excellent intra-class correlation coefficients (ICC single measures $.89(.83, .92), p<.001)$. When interrater reliability had been established, the remaining 68 videotapes were scored by $\mathrm{JK}$. The coding of these films generated a count for each communication skill, with a higher score indicating greater skills.

Focus groups

Participants were invited to discuss how they experienced participation in the simulation training with actors. The interview guide included the following questions: 'How did you experience participating in the simulation training?', 'What do you perceive you were training?', 'How did the simulation training change your communication skills?', and 'How did the simulation training affect your patient relations?'. Followup questions were asked when appropriate. The interviews were audio-recorded and lasted for about 3248 minutes, and were then transcribed verbatim and pseudonymised with sex. The interviews were performed by one graduate student (JK) and one psychologist trained in CS. The interviewers did not participate in the education/simulation training and were trained in interviewing techniques by one of the authors (JI) who is experienced in this method.

\section{Data analyses}

Results are presented as means and standard deviations. For the first aim, independent sample (Student's) t-tests were used for comparing ratings on the evaluation form between those who had the simulation training with actors and those who had only roleplay with peers. For the second aim, a multivariate analysis of covariance (MANCOVA) was performed using the Statistical Package for the Social Sciences (SPSS-26), in order to assess differences in the dependent variables active listening, the quota open-ended/closed-ended questions, empathy and total use of CS (i.e., summation of active listening, motivational efforts and empathy) with before and after training as independent variables. We also adjusted for covariates such as sex, length of videotape and SP case in the MANCOVA. The 
MANCOVA yields partial eta squared ( $\eta 2)$, a common metric of effect size that represents the unique amount of variance explained by each independent variable, with $\eta 2=.01$ being regarded as a small effect size, .06 as medium and .14 as large. Motivational efforts were not included as a dependent variable in the MANCOVA due to the extremely low use of these skills, both before and after training. Normal distribution could be seen, except as regards the quota, but the same results were generated for non-parametrical and parametrical values. Two-tailed tests with $p$-values $<.05$ were considered to be statistically significant.

For the third aim, a qualitative content analysis [35] was carried out using an inductive approach where the categories were derived from the data [36]. The analysis was conducted by two of the authors (JI \& MR), who continuously discussed and confirmed the findings. First, the material was read to achieve an optimal understanding of the content. Second, all meaning units, defined as one or more sentences or just part of one sentence, carrying a meaning connected to the research question, were extracted. Third, the meaning units were shortened to their essence. Fourth, text units with similar meaning were grouped into mutually exclusive categories. Fifth, categories were divided into subcategories based on dissimilarities within the categories. To increase the rigor of the analysis, the interview text was reread and the categories and subcategories were compared and validated against the text.

\section{Results}

\section{Evaluation form}

As shown in Table 1, students who participated in the simulation training with actors reported higher satisfaction with the course and the feedback from teachers. No differences were found in satisfaction with the seminars/work in groups or the opportunity to be active.

Table 1 Group comparisons of course evaluations between medical students who had the simulation training with actors (after SP, $N=36$ ) and those who had not (before $S P, N=57$ ), using independent sample t-test. 


\begin{tabular}{|lllll|}
\hline & $\begin{array}{l}\text { Before } \\
\text { SP }\end{array}$ & $\begin{array}{l}\text { After } \\
\text { SP }\end{array}$ & Statistics \\
& $\begin{array}{l}\text { Mean } \\
(\text { SD) }\end{array}$ & $\begin{array}{l}\text { Mean } \\
\text { (SD) }\end{array}$ & \\
What is your overall review of the course? & 4.2 & 4.8 & $\mathrm{t}=2.12^{*}$ \\
& $(1.2)$ & $(1.4)$ & \\
\hline How satisfied are you with the seminars/work in groups? & 4.4 & 5.0 & $\mathrm{t}=1.44$ \\
& $(2.3)$ & $(1.7)$ & \\
\hline $\begin{array}{l}\text { Too what degree do you think the teachers have given you valuable } \\
\text { feedback on your work? }\end{array}$ & $\begin{array}{l}4.4 \\
(1.6)\end{array}$ & $\begin{array}{l}5.1 \\
(1.4)\end{array}$ & $\mathrm{t}=2.22^{*}$ \\
\hline $\begin{array}{l}\text { Too what degree do you think you were given the opportunity to be } \\
\text { active? }\end{array}$ & $\begin{array}{l}4.9 \\
(2.3)\end{array}$ & $\begin{array}{l}5.4 \\
(1.1)\end{array}$ & $\mathrm{t}=1.41$ \\
\hline
\end{tabular}

Note $* \mathrm{p}<0.05$. All items were rated from $1=$ 'not (content) at all' to $6=$ 'very content $/ \mathrm{much}^{\prime}$

Use of communication skills

Mean values of CS are presents in Supplementary Table 3, split by sex. The results from the MANCOVA with the effect sizes of the independent variables on the outcome of each dependent variable, as well as the total score statistics, are presented in Table 2. The full model explained $27 \%$ of the variance in the total use of CS, $30 \%$ of that of active listening and $19 \%$ of that of empathic responses. The simulation training with SP had no effect on the total amount of CS used, nor on active listening. There was a trend $(b=1.6 ; p=.099)$ towards increased empathy after simulation training. Females showed more empathy than males. There was a main effect for the length of the consultation on the use of total CS and active listening, which can be explained by longer conversations.

Table 2 MANCOVA with the dependent variables (total communication skills, active listening, empathy and quote of open ended questions/closed-ended questions regressed on the independent variables (sex, time, case, training) 


\begin{tabular}{|c|c|c|c|c|c|}
\hline & $\begin{array}{l}\text { Summary statistics } \\
\text { (Wilks' lambda, [df]F-value, } \\
\eta^{2}, p \text {-value) }\end{array}$ & & $\begin{array}{l}\text { Parameter } \\
\left(b, \eta^{2}\right)\end{array}$ & imates & \\
\hline & & Total $^{e}$ & $\begin{array}{l}\text { Active } \\
\text { listening }\end{array}$ & Empathy & $\begin{array}{l}\text { Quote } \\
f\end{array}$ \\
\hline $\begin{array}{l}\text { Sex } \\
\text { (reference=male) }\end{array}$ & $0.85,(1) 2.80,0.16, .034$ & $\begin{array}{l}0.02 \\
0.00\end{array}$ & $-2.10,0.01$ & $\begin{array}{l}2.13 \\
0.13^{\star *}\end{array}$ & $\begin{array}{l}2.58 \\
0.01\end{array}$ \\
\hline Time & $0.86,(1) 2.44,0.14, \mathrm{~ns}$ & $\begin{array}{l}1.69 \\
0.10^{\star \star \star}\end{array}$ & $\begin{array}{l}1.72 \\
0.11^{\star \star}\end{array}$ & $\begin{array}{l}-0.02 \\
0.00\end{array}$ & $\begin{array}{l}0.68 \\
0.03\end{array}$ \\
\hline Case & $0.70,(5) 1.13,0.08, \mathrm{~ns}$ &,- 0.12 &,- 0.14 &,- 0.07 &,- 0.03 \\
\hline Training & $0.90,(1) 1.67,0.10, \mathrm{~ns}$ & $\begin{array}{l}-6.06 \\
0.02\end{array}$ & $-7.50,0.04$ & $\begin{array}{l}1.63 \\
0.04\end{array}$ & $\begin{array}{l}-3.07 \\
0.01\end{array}$ \\
\hline
\end{tabular}

Note** $<0.01$

१2 = partial eta squared

Focus groups

As shown in Table 3, the qualitative analysis resulted in five categories and 15 subcategories. These are presented below with quotes that reflect each subcategory.

Feedback

The subcategory Constructive feedback included statements about feedback received within the groups, where concrete suggestions on how to change behaviours were regarded as very helpful. In Basis for good feedback, the students discussed the importance of having a common understanding of, and format for, how feedback should be delivered, and the need for an accepting and permissive climate in the group. As one student commented 'the strength of the course is that you expose all your limitations in CS in front of ten people, and that obviously requires a supportive learning climate'. In How much feedback, some thought that it was good with a lot of feedback, while others thought that too much time was spent on feedback, especially when all the students were asked to give feedback, and the same comments were repeated. Comments on whether feedback should be given During or after simulation varied, with some students describing the benefits of getting feedback during the simulation, so changes in relation to the SP could be implemented immediately. Others highlighted the risk of interruptions interfering with the consultation progress. In the last subcategory, From whom?, it appeared that feedback from the SP was highly appreciated.

Working with SPS 
It was discussed that the use of SPs (actors) made the simulation more Realistic as compared with roleplay with a fellow student. Some thought it was not as realistic as having a real patient.

The cases

In the subcategory Implementation, the students expressed appreciation for the opportunity to choose what emotions, e.g., angry, sad, manipulative, the SP should portray. There were comments about how the supervisors led the sessions, and the students reacted negatively when the supervisor was not prepared or talked too much. The opportunity to ask for a timeout and get help from the group and the supervisor was appreciated. In Scenarios, the students emphasised the benefits of the actors being able to change their portrayed character, so that the next student acting as the physician did not have to repeat the exact same simulation.

The learning process

The students discussed that the simulation training with actors enabled them To practice difficult consultations in a safe way. Some took the opportunity to practice handling emotions expressed by patients that they felt were hard to deal with, e.g., anger. One student said: 'I felt it was ... special to see a patient who became really angry, first angry and then furious. I am not used to dealing with people's anger, so it is very good to be able to practice.' Some students mentioned that it was useful to experience not being able to effectively manage the SP's reactions, for instance not being able to give reflections on the actor's anger. The experience of delivering bad news to the SPs was also appreciated by the students. In the subcategory Amount of training, the opportunity to test or observe different difficult consultations was described as positive. Some argued that it would have been good to act as physician in more consultations. Another learning process discussed was To handle own feelings in the consultations: 'To handle one's feelings, to deliver bad news, read the body language, to use one's own body language. To sit closer to someone who is sad, keep a respectful distance to someone who is angry ...'

Lessons learned

Specific techniques that the students discussed as being trained in the simulations were motivational efforts (working with the SP's ambivalence) and delivering bad news. Another consequence of the simulations was Increased experience and the students described being better prepared for the future thanks to having practiced difficult conversations: 'The day when I meet a patient who is very angry with me, I will be happy that I have at least met an actor who was really angry with me.' It was stated that simply having established a contact with the patient was acceptable and that you could not always reach a solution: 'Then I will do my best ... and even if it is not completely under my control, that's okay.'

Changes in communication skills that were discussed were the experience of having better conversations after training, a better ability to create an alliance with patients and to keep calm, and being better at giving feedback.

Relevance

Page 10/19 
It was discussed if the simulations with SPs were Relevant; especially those who had worked with psychiatric patients felt that they were. Others stated that some skills were Irrelevant, such as delivering bad news which one believed would not be realised for many years. Others felt that these skills could not be fully practiced in the clinics due to lack of time and the inappropriateness of a student doing it, and some thought that the extremely difficult consultations practiced during this course were not common in real life.

Suggestions for change

Some suggested that the simulations with SPs should have been Offered earlier, before the course in psychiatry or even earlier in the programme. The need for Smaller groups was discussed, with more time for each student to practice. In order to minimise discussions on who should play the physician in a simulation, it was suggested that it could be decided beforehand who would have this role in each case. Talking about suicide and giving bad news to a relative were suggested as Other cases.

Table 3 Categories and subcategories in the qualitative analyses 


\begin{tabular}{|c|c|}
\hline Categories & Subcategories \\
\hline \multirow[t]{4}{*}{ Feedback } & Constructive feedback \\
\hline & $\begin{array}{l}\text { Basis for good feedback } \\
\text { How much feedback }\end{array}$ \\
\hline & During or after simulation \\
\hline & From whom? \\
\hline Working with SPs & Realistic \\
\hline \multirow[t]{2}{*}{ The cases } & Implementation \\
\hline & Scenarios \\
\hline \multirow[t]{3}{*}{ The learning process } & To practice difficult consultations \\
\hline & Amount of training \\
\hline & To handle own feelings \\
\hline \multirow[t]{3}{*}{ Lessons learned } & Specific techniques \\
\hline & Increased experience \\
\hline & Changes in communication skills \\
\hline \multirow[t]{2}{*}{ Relevance } & Relevant \\
\hline & Irrelevant \\
\hline \multirow[t]{3}{*}{ Suggestions for change } & Offered earlier \\
\hline & Smaller groups \\
\hline & Other cases \\
\hline
\end{tabular}

\section{Discussion}


In this mixed-method study, we evaluated simulation training in challenging situations with actors as SPs for training medical students' CS. The students who got the training evaluated the course more positively than students from previous term, when SPs were not used in the training. The simulation training with SPs did not result in the use of more CS, such as active listening, empathic responses and MI techniques, among the students, when compared with students from the previous term. In the interviews, it was stated that using actors as SPs made the simulations more realistic. Elements such as constructive feedback, the actors' flexibility in changing character, and being exposed to negative emotions were regarded as factors in the learning process. Being better prepared for the future and being more able to build alliances with patients were mentioned as positive results in the interviews. While some students found the simulations to be relevant, others did not.

The higher ratings in overall reviews of the course and satisfaction with the feedback from supervisors are in line with previous research, with reports of an appreciation of including SPs in teaching and learning [37]. For instance, medical students rated having encounters with SPs highly and expressed increased comfort with addressing difficult topics with patients [28, 29]. Using SPs has been reported to be more effective in increasing self-confidence among nursing students [38]. Interprofessional healthcare professionals and teachers stated that the use of SPs, via both direct participation in and observation of the enactment, was associated with an increased sense of realism, and actor feedback was highlighted as a key component in learning [27]. In line with this finding, the qualitative analysis from the focus groups showed that feedback from the SP was highly appreciated and that the use of actors made the simulation more realistic, as compared with peer roleplay. Previous research has discussed the limitations with peer roleplaying, which depends on students' abilities to portray patients and give realistic responses $[23,38]$. In our study, the flexibility of the actors in changing their acting/character was also highlighted as important in the learning process.

SPs are mainly used as a tool for evaluating students. However, since there is immense learning potential for students in working with SPs as a teaching resource, the method has the potential to be effective in CS education [26]. Contradicting our hypothesis, the simulation training with SPs did not result in the use of more CS as compared with during the previous term. The students interacting with SPs did not show higher frequencies of active listening, empathic responses or Ml techniques in the video recordings. Previous literature has reported an effect of SPs on CS. In a randomised controlled study, where medical students were randomised to training with SPs (or conventional lectures), those who trained with SPS used more open and closed questioning techniques, encouraged patient responses, invited the patients to clarify missing items, showed more encouragement of the patient's emotions, and were better at managing the time and performance of the interview [31]. However, in the study by Geoffroy and colleagues, the students were observed during an interview and no challenging behaviours were targeted. In a study where students were instructed to deliver bad news to a SP, those who had previously practised breaking bad news to a SP performed better on CS as rated by the SP than students with no training [33]. Despite these examples, reviews on the effects of using SPs to enhance knowledge or skill development among professionals have concluded that there are few rigorous outcome studies of medical education programmes or physical therapy education $[30,39]$. Although the educational use of SPs is rated as 
valuable, more rigorous studies are needed to support the evidence-based use of SPs in teaching and learning [37]. In addition, previous studies seldom include a wider range of challenging behaviours, exploring both feasibility and measurable behavioural effects. Thus, more research regarding the effectiveness of employing SPs in education is needed, and although our results do not suggest any effect of SP, we would need either a randomised controlled design to better approach this specific research question or an assessment of CS before training in order to see any development of CS at an individual level.

Female students showed significantly more empathic behaviours, both before and after training. This association between empathy and sex has been confirmed in several other studies, with female students consistently showing higher empathy levels [14, 40-42]. The students' use of motivational efforts during the examinations was extremely low, and therefore it is difficult to draw definite conclusions about any possible influence of the implemented training. A possible explanation could be that the setting with a practical examination and the types of cases used did not encourage the use of motivational efforts. Use of motivational efforts was not mandatory for students to pass their practical examination and it is possible that students mainly focused on using the skills necessary for them to pass the examination.

Regarding our last aim, i.e., to explore via interviews how the students experienced simulation training using SPs, the students expressed an appreciation for the actors' flexibility and the opportunity to choose what emotions the SP should show. The training with SPs enabled them to practice difficult consultations - such as managing angry patients or delivering bad news in a patient-centred way - and handling their own feelings. Some also described a feeling of having better conversations and a better ability to create an alliance with patients after the training. Feedback was mentioned as an important element, but also as something that created stress, especially if there was not a constructive climate in the group. Some also said that too much time was spent on feedback and wished for more practice with the SPs. In line with this, students suggested smaller groups with more time for each student to practice. Simulations with SPs were mostly regarded as relevant, but one concern raised was that these skills could not be used when the students were medical doctors, due to lack of time and that clinicians do not use them.

\section{Limitations}

Our study had some limitations that need to be taken into consideration. First, this was a cross-sectional study, not a longitudinal study following the same cohort before and after training. Because of this, and the relatively small sample groups, unmeasured factors may have resulted in baseline differences between the cohorts, obscuring the potential impact or the results. In the future, longitudinal and randomised control designs should be applied. Second, the researcher viewing the videos had knowledge of whether the examinee had received training or not. This could potentially result in a positive bias for the students who had received training. In future studies, blinding of the viewer would eliminate any potential observer bias. Other studies have used SPs as evaluators of students' CS performances, which could be an alternative, but downsides of this strategy are a possible affective influence and lack of 
professional competence $[43,44]$. Third, the rating tool used was designed specifically for this study and has thus not been tested regarding internal and external validity. Still, the rating was based on CS in a straightforward manner. Fourth, the limited sample size with students from one Swedish medical school and a possible selection bias due to the voluntary participation in the study may limit the generalisability of the results. By contrast, the strengths of this study were the mixed design, combining quantitative and qualitative data, several challenging situations using SPs being used. It is of great interest to include difficult cases, such as negative patient reactions and unmotivated patients, when evaluating training of CS since CS are of particular importance and put to the test in such instances.

\section{Conclusion}

We conclude that the use of SPs in education of CS among medical students is feasible and appreciated, but we find no effect of simulation training with SPs on the use of CS such as active listening, increased empathy or Ml techniques. Future studies should include baseline levels for the students before training and apply a randomised control design. Future research could also aim to explore any effects from training over time, as well as to determine the cost-effectiveness of such efforts, considering that SPs are more expensive than for example roleplay. When using SPs in the education, a flexibility of the actors to change character, offering the students a choice of negative emotions from the SPs, and giving the students the opportunity to train with SPs on different types of challenging situations seem to be of importance. The feedback process should be in focus, to promote constructive feedback within the group and encourage the SPs to give feedback. As it is essential to train future medical doctors in CS, evaluation of these skills and how they are taught in the best way is of utmost importance.

\section{Declarations}

\section{Acknowledgements}

The authors wish to thank participating students and Uppsala University Hospital.

\section{Authors' contributions}

All authors contributed to the writing of the manuscript and reviewed the final manuscript. Jl conducted data analysis. The author(s) read and approved the final manuscript.

\section{Funding}

The research was supported by Uppsala University.

\section{Availability of data and materials}

The data that support the findings of this study are available on reasonable request from the corresponding author. The data are not publicly available due to privacy or ethical restrictions. 


\section{Ethics approval and consent to participate}

All procedures performed in studies involving human subjects were in accordance with the ethical standards of the Swedish Ethical Review Authority (Dnr 2019-05908) and with the 1964 Helsinki declaration and its later amendments or comparable ethical standards. Approval and written informed consent to participate was obtained from all study participants.

\section{Consent for publication}

All subjects involved in both methods have provided informed consent for publication.

\section{Competing interests}

Authors have no competing interests to disclose.

\section{References}

1. Larsen JH, Risør O, Putnam S. P-R-A-C-T-I-C-A-L: A step-by-step model for conducting the consultation in general practice. Fam Pract. 1997;14(4):295-301. https://doi.org/10.1093/fampra/14.4.295

2. Marcinowicz L, Górski S. Medical consultation and communication with a family doctor from the patients' perspective - a review of the literature. Fam Med Prim Care Rev. 2016;18:387-390. https://doi.org/10.5114/fmpcr/62676

3. Nystrup J, Larsen J-H, Risør O. Developing Communication Skills for the General Practice Consultation Process. Sultan Qaboos Univ Med J. 2010;10(3):318-325.

4. Rautalinko E. Samtalsfärdigheter-Stöd, vägledning och ledarskap (2nd ed.). 2013. Liber AB.

5. Hojat M, Vergare MJ, Maxwell K, Brainard G, Herrine SK, Isenberg GA, et al. The Devil is in the Third Year: A Longitudinal Study of Erosion of Empathy in Medical School. Acad Med. 2009;84(9):11821191. https://doi.org/10.1097/ACM.0b013e3181b17e55

6. Bas-Sarmiento P, Fernández-Gutiérrez M, Baena-Baños M, Correro-Bermejo A, Soler-Martins PS, de la Torre-Moyano S. Empathy training in health sciences: A systematic review. Nurse Educ Pract. 2020;44:102739. https://doi.org/10.1016/j.nepr.2020.102739.

7. Hojat M, Louis DZ, Markham FW, Wender R, Rabinowitz C, Gonnella JS. Physicians' empathy and clinical outcomes for diabetic patients. Acad Med. 2011;86(3):359-364. https://doi.org/10.1097/ACM.0b013e3182086fe1

8. Zolnierek KB, DiMatteo MR. Physician Communication and Patient Adherence to Treatment: A Metaanalysis. Med Care. 2009; 47(8):826-834. https://doi.org/10.1097/MLR.0b013e31819a5acc

9. Boissy A, Windover AK, Bokar D, Karafa M, Neuendorf K, Frankel RM, Merlino J, Rothberg MB. Communication Skills Training for Physicians Improves Patient Satisfaction. J Gen Intern Med. 2016;31(7):755-761. https://doi.org/10.1007/s11606-016-3597-2 
10. Howick J, Moscrop A, Mebius A, Fanshawe TR, Lewith G, Bishop FL, Mistiaen P, Roberts NW, Dieninyte E, Hu XY, Aveyard P, Onakpoya IJ. Effects of empathic and positive communication in healthcare consultations: A systematic review and metaanalysis. J R Soc Med. 2018;111(7):240252. https://doi.org/10.1177/0141076818769477

11. Lelorain S, Brédart A, Dolbeault S, Sultan S. A systematic review of the associations between empathy measures and patient outcomes in cancer care. Psycho-Oncology. 2012);21:1255-1264. https://doi.org/10.1002/pon.2115

12. Miller WR, Rollnick S. Motivational Interviewing: Helping People Change. 2012. Guilford Press.

13. DiClemente CC, Corno CM, Graydon MM, Wiprovnick AE, Knoblach DJ. Motivational interviewing, enhancement, and brief interventions over the last decade: A review of reviews of efficacy and effectiveness. Psychol Addict Behav. 2017;31(8):862-887. https://doi.org/10.1037/adb0000318

14. Chen DCR, Kirshenbaum DS, Yan J, Kirshenbaum E, Aseltine RH. Characterizing changes in student empathy throughout medical school. Med Teach. 2012;34(4):305-311.

https://doi.org/10.3109/0142159X.2012.644600

15. Shashikumar R, Chaudhary R, Ryali V, Bhat PS, Srivastava K, Prakash J, Basannar D. Cross sectional assessment of empathy among undergraduates from a medical college. Med $\mathrm{J}$ Armed Forces India. 2014;70(2):179-185. https://doi.org/10.1016/j.mjafi.2014.02.005

16. Batt-Rawden SA, Chisolm MS, Anton B, Flickinger TE. Teaching Empathy to Medical Students: An Updated, Systematic Review. Acad Med. 2013;88(8):1171-1177.

https://doi.org/10.1097/ACM.0b013e318299f3e3

17. Neumann, M, Edelhäuser, F, Tauschel $D$ et al. Empathy decline and its reasons: a systematic review of studies with medical students and residents. Acad Med. 2011;86:996-1009.

18. Fallowfield $L$, Jenkins V. Communicating sad, bad, and difficult news in medicine. Lancet. 2004;363(9405):312-319. https://doi.org/10.1016/S0140-6736(03)15392-5

19. Hulsman RL, Pranger S, Koot S, Fabriek M, Karemaker JM, Smets EM. A. How stressful is doctorpatient communication? Physiological and psychological stress of medical students in simulated history taking and bad-news consultations. International Journal of Psychophysiology. 2010;77(1), 26-34. https://doi.org/10.1016/j.jpsycho.2010.04.001

20. Andersson SO, Cavalli-Björkman N. Krävande möten och svåra besked. Professionell utveckling inom läkaryrket. 2012. Liber AB.

21. Chipidza F, Wallwork RS, Adams TN, Stern TA. Evaluation and Treatment of the Angry Patient. Prim Care Companion CNS Disord. 2016;18(3). https://doi.org/10.4088/PCC.16f01951

22. Billings JA, Block S. Palliative Care in Undergraduate Medical Education: Status Report and Future Directions. JAMA. 1997;278(9):733-738. https://doi.org/10.1001/jama.1997.03550090057033

23. Rosenbaum ME, Ferguson KJ, Lobas JG. Teaching Medical Students and Residents Skills for Delivering Bad News: A Review of Strategies. Acad Med. 2004;79(2):107-117.

24. Howley LD, Gliva-McConvey G, Thornton J. Standardized patient practices: Initial report on the survey of US and Canadian medical schools. Med Educ Online. 2009;14,7. 
https://doi.org/10.3885/meo.2009.F0000208

25. Passiment M, Sacks H, Huang G. Medical Simulation in Medical Education: Results of an AAMC Survey. Washington, DC: Association of American Medical Colleges. 2011.

26. Talwalkar JS, Cyrus KD, Fortin AH. Twelve tips for running an effective session with standardized patients. Med Teach. 2020;42:6: 622-627. https://doi.org/10.1080/0142159X.2019.1607969

27. Bell SK, Pascucci R, Fancy K, Coleman K, Zurakowski D, Meyer EC. The educational value of improvisational actors to teach communication and relational skills: Perspectives of interprofessional learners, faculty, and actors. Patient Educ Couns. 2014;96(3):381-388. https://doi.org/10.1016/j.pec.2014.07.001

28. Kiluk JV, Dessureault S, Quinn G. Teaching Medical Students How to Break Bad News with Standardized Patients. J Cancer Educ. 2012;27(2):277-280. https://doi.org/10.1007/s13187-0120312-9

29. Rosenbaum ME, Kreiter $C$. Teaching delivery of bad news using experiential sessions with standardized patients. Teach Learn Med. 2002;14(3):144-

149. https://doi.org/10.1207/S15328015TLM1403_2

30. Wilbur K, Elmubark A, Shabana S. Systematic Review of Standardized Patient Use in Continuing Medical Education. J Contin Educ Health Prof. 2018;38:3-10. https://doi.org/10.1097/CEH.0000000000000190

31. Geoffroy PA, Delyon J, Strullu M, Dinh AT, Duboc H, Zafrani L et al. Standardized Patients or Conventional Lecture for Teaching Communication Skills to Undergraduate Medical Students: A Randomized Controlled Study. Psychiatry Investig. 2020;17(4):299-305. https://doi.org/10.30773/pi.2019.0258

32. Paramasivan A, Khoo D. Standardized Patients Versus Peer Role Play-Exploring the Experience, Efficacy, and Cost-Effectiveness in Residency Training Module for Breaking Bad News. J Surg Educ. 2020;77:479-484.

33. Colletti L, Gruppen L, Barclay M, Stern D. Teaching students to break bad news. The Am J Surg. 2001;182(1):20-23. https://doi.org/10.1016/S0002-9610(01)00651-1

34. Cömert M, Zill JM, Christalle E, Dirmaier J, Härter M, Scholl I. Assessing Communication Skills of Medical Students in Objective Structured Clinical Examinations (OSCE)-A Systematic Review of Rating Scales. PLOS ONE. 2016;11(3), e0152717. https://doi.org/10.1371/journal.pone.0152717

35. Krippendorff K. Content analysis: An introduction to its methodology (2nd edn). 2004. Thousand Oaks, CA: Sage Publications.

36. Elo S, Kyngäs H. The qualitative content analysis process. J Adv Nurs. 2008;62(1):107-115. https://doi.org/10.1111/j.1365-2648.2007.04569.x

37. May W, Park JH, Lee JP. A ten-year review of the literature on the use of standardized patients in teaching and learning: 1996-2005. Med Teach. 2009;31:6:487-492.

https://doi.org/10.1080/01421590802530898 
38. Cahyono BD, Zuhroidah I, Sujarwadi M. Effectiveness of Standardized Patients and Role-Play Simulation Methods in Improving Self-Confidence and Therapeutic Communication Skills of Nursing Students. Nurse and Health: Jurnal Keperawatan. 2020;9(1):9-15. http://ejournalkertacendekia.id/index.php/nhjk/index

39. Pritchard SA, Blackstock FC, Nestel D, Keating JL. Simulated Patients in Physical Therapy Education: Systematic Review and Meta-Analysis. Phys Ther. 2016;96(9):1342-1353. https://doi.org/10.2522/ptj.20150500

40. Graf J, Smolka R, Simoes E, Zipfel S, Junne F, Holderried F, et al. Communication skills of medical students during the OSCE: Gender-specific differences in a longitudinal trend study. BMC Med Educ. 2017;17(1),75. https://doi.org/10.1186/s12909-017-0913-4

41. Hojat M, Gonnella JS, Mangione S, Nasca TJ, Veloski JJ, Erdmann JB, et al. Empathy in medical students as related to academic performance, clinical competence and gender. Med Educ. 2002;36(6):522-527. https://doi.org/10.1046/j.1365-2923.2002.01234.x

42. Kataoka HU, Koide N, Ochi K, Hojat M, Gonnella JS. Measurement of empathy among Japanese medical students: Psychometrics and score differences by gender and level of medical education. Acad Med. 2009;84(9):1192-1197. https://doi.org/10.1097/ACM.0b013e3181b180d4

43. Alanazi AA, Nicholson N, Thomas S. The Use of Simulation Training to Improve Knowledge, Skills, and Confidence Among Healthcare Students: A Systematic Review. 2017;15(3).

44. Epstein RM, Hundert EM. Defining and Assessing Professional Competence. JAMA. 2002;287(2):226-235. https://doi.org/10.1001/jama.287.2.226

\section{Supplementary Files}

This is a list of supplementary files associated with this preprint. Click to download.

- SupplementaryTable1.docx

- SupplementaryTable2.docx

- SupplementaryTable3.docx 